\title{
Predicación y reforma en el contexto católico europeo previo a Trento
}

\author{
Predikua eta erreforma Trento baino lehenagoko Europako testuinguru \\ katolikoan
}

Preaching and Reformation in the European Catholic Context previous to Trent

\author{
Miǵuel Anxo Pena González \\ Universidad Pontificia de Salamanca \\ mapenago@upsa.es \\ https://orcid.org/0000-0002-6760-9596
}

Recibido / Noiz jaso den: 14/02/2021

Aceptado / Noiz onartu den: 16/03/2021

\section{Resumen}

El presente artículo se acerca al contexto generado por la reforma, en la primera mitad del siglo XVI, en el contexto católico, donde la predicación se convierte en un elemento de primer nivel. En este sentido, se leen en una perspectiva más amplia algunos elementos que tradicionalmente se han interpretado como vinculación con un pasado medieval, pero que tienen ya mucho que ver con la modernidad y un incipiente humanismo cristiano. Propuestas tempranas como las de Antonio de Nebrija y Pedro Ciruelo -que son analizadas en el presente trabajo- no estarán tan distantes de las expresadas en el V Concilio de Letrán o en las propuestas siempre sugerentes de Erasmo. Sin lugar a dudas, la propuesta del Maestro Ávila se presenta como una proyección de dichas ideas, pero que viene completada desde la coherencia de la propia vida.

\section{Palabras clave}

Predicación; reforma; humanismo cristiano; Pedro Ciruelo; Erasmo; Maestro Ávila.

\section{Sumario}

1. El CONTEXto de Reforma. 2. Los albores de unA NuEVA SENSIBILIDAD. 3. El ECCLESIASTES DE ERASMO dE RÓteRdam. 4. SAN JuAN de ÁVILA: UNA VIDA DEDICADA a LA PREDICACIÓN. 5. CONCLUSIONES. BIBLIOGRAFÍA. 


\begin{abstract}
Laburpena. XVI. mendearen lehen erdialdean izandako erreforma katolikoaren ondorioz, predikua lehen mailako elementu bilakatu zen, eta garai hartako testuingurua aztertzen da artikulu honetan, hain zuzen ere. Alde horretatik, tradizioz Erdi Aroarekin lotu izan diren zenbait elementu ikuspegi zabalagoarekin aztertzen dira, zerikusi handia baitute bai Aro Modernoarekin, baita humanismo kristau hasiberriarekin ere. Antonio de Nebrijaren eta Pedro Cirueloren proposamen goiztiarrak -lan honetan aztertutakoak- ez daude oso urruti Laterango V. Kontzilioan aditzera eman ziren haietatik edo Erasmoren proposamen iradokitzaileetatik. Zalantzarik gabe, Ávila maisuaren proposamena ideia horien proiekzio moduan ageri da, baina norberaren bizitzaren koherentziarekin osatua.
\end{abstract}

Gako hitzak. Predikua; erreforma; humanismo kristaua; Pedro Ciruelo; Erasmo; Ávila Maisua.

\begin{abstract}
This article approaches the context generated by the Reform, in the first-half of the Xvith Century, in the Catholic sphere, where preaching becomes a first-level element. Some elements are read in a broader perspective, which traditionally they have been interpreted as a link with a Medieval past, but they already have much to do with Modernity and an incipient Christian Humanism. In this sense, early proposals such as those of Antonio de Nebrija and Pedro Ciruelo -which are analyzed in the present work- will not be so far removed from those expressed in the Vth Lateran Council or in the always suggestive proposals of Erasmus. Maestro Ávila's proposal is presented as a projection of these ideas, but which is completed from the coherence of his life.
\end{abstract}

Keywords. Preaching; Reformation; Christian Humanism; Pedro Ciruelo, Erasmus, John of Ávila.

La historia cultural cuenta con múltiples elementos para acercarse a la realidad de la Edad Moderna. Uno de ellos es el amplio y vasto tema de la predicación, que necesariamente ha de ser abordado con una mirada amplia. Es por eso que lo consideramos en relación a la historia cultural y no solo a la historia religiosa.

El estudio y la preocupación por la oratoria tenía un largo recorrido, que se remontaba a los orígenes del cristianismo, vinculado además con el contexto clásico y, por lo mismo, con los autores más relevantes del mundo latino. No habrá momento de la historia en el que la predicación no haya sido tenida en cuenta, tanto desde el ámbito religioso como desde el cultural o político. Por otra parte, teniendo presente el marco temporal que supone el final del siǵlo XV y el comienzo del siǵlo XVI, donde la confrontación y la crisis son dos elementos identificadores, es obvio que esta tuvo que ser un elemento crucial, siendo incluso considerada como un posible medio o herramienta al servicio de las preocupaciones y a las concretas facciones en liza.

El campo de lo religíioso, particularmente de la vida litúrǵica, y, por lo mismo, también la predicación, era un tema que concitaba y preocupaba a una amplia mayoría de gente en el contexto europeo. No dejaba de ser el medio más oportuno y eficaz para influir en la conciencia de las gentes y de los pueblos. Los predicadores, ya fueran populares o cortesanos, podían orientar y dirigir, de alguna manera, el hacer y sentir de las gentes de cada época. Según González Novalín, 
la predicación era «en aquella época un método de penetración religiosa, cuya forma estaba sometida a crítica y revisión ${ }^{1}$.

Como ocurría con otros temas vinculados a lo religioso, tenía un amplio recorrido con matices y expresiones diferentes que refería también a los contextos culturales específicos donde era llevada a cabo. Por este motivo, en muchos momentos se ha entendido el tema de la predicación como un ámbito de contraste entre una lectura que podríamos llamar católica y otra más próxima al ámbito protestante. No es muy difícil suponer que esto no es tan simple, ni funciona de forma matemática. Es cierto que podemos encontrar amplios puntos de coincidencia, incluso en aquello que tradicionalmente se ha considerado como propio y distante entre sí, pero también habrá otras cuestiones en las que la tónica predominante será la distancia intelectual y cultural. Algo que influyó fuertemente en la predicación fueron los contextos de reforma, unos de orientación moralizante $\mathrm{y}$ otros de tendencia humanista, que intentaban conquistar el auditorio. Ambos suponen también una comprensión de la vida, a la que hemos de hacer referencia con atención.

Reflexiones distantes en el tiempo, como las de Eugenio Asensio, siguen poniendo de relieve la interdependencia y los lugares comunes que podemos encontrar entre autores que, de partida, consideraríamos fuertemente distantes ${ }^{2}$. Y, en este sentido, lo que decimos de los autores lo podemos también afirmar en relación a los movimientos o a los grupos de presión de un determinado momento histórico.

Es obvio que no pretendemos ser exhaustivos en esta lectura, sino que queremos acercarnos y poner de relieve aquellos acentos que manifiestan la peculiaridad del momento histórico. Las decisiones tomadas en las sesiones conciliares, así como la actitud beligerante de unos y otros, han influido hondamente en aquello que se ha afirmado y en cómo se ha hecho, pero no lo ha determinado todo, pues una cosa era el discurso oficial y, otra, a veces muy distinta, lo que se llevaba a la práctica. Por otra parte, acercarnos a las décadas previas a Trento, nos habla de un momento crucialmente rico, en el que las cosas no estaban tan definidas como se pretenderá luego hacer ver.

Bataillon puso de relieve como Erasmo fue, para los hispanos, un renovador de la piedad, pero reconociendo también que, muchas veces, se le han podido atribuir cuestiones que tienen una tradición diversa y, posiblemente, más prolongada en el tiempo. Como defendía el mismo Asensio, cuando varios autores han pertenecido a una misma generación y han vivido idénticas problemáticas

1 González Novalín, 1980, p. 367.

2 Asensio, 2000, pp. 39-44. La primera edición es la del año 1952, pero utilizamos esta edición por estar particularmente bien acabada. 
-él ponía el ejemplo de Erasmo y Barbosa- "¡Qué difícil es discernir y separar estas naturales concomitancias!» (p. 98).

El momento que nos ocupa está marcado todavía por un ambiente de búsqueda, de libertad y de serio debate religioso, que se irá dificultando y enrareciendo paulatinamente, fundamentalmente como consecuencia de la crisis alumbrada y erasmista, que podríamos ubicar entre 1524 y 1535. El fracaso de las conversaciones teológicas con los reformadores en el contexto del sacro Imperio, así como la opción de Carlos V por la vía armada, harán también que los acontecimientos se orienten en una línea concreta. No hay duda de que el espacio previo a Trento tiene una personalidad propia y diversa de lo que vendrá después, que, por otra parte, en relación a la predicación, es aquello en lo que los autores han hecho más hincapié, orientándose ya hacia una manualística y ars praedicandi.

\section{El contexto de reforma}

El marco temporal que nos ocupa está determinado fuertemente por un ansia de reforma. Se trata de una preocupación central y constante en la mayoría de los autores. No era algo nuevo, sino que dicha sensibilidad era recurrente desde los ya lejanos concilios II y III de Letrán. Con todo, un momento de inflexión importante es el que tiene lugar con la celebración del último de los concilios lateranenses -el quinto- que discurre entre 1512 y 1517, abarcando los pontificados de Julio II y León X. Los participantes al mismo llegan con la idea clara -sostenida por todos- de que es preciso reformar, pero la cuestión más compleja es cómo concretar esa idea, cómo llevarla a efecto y con qué herramientas. No hay duda de que, en gran parte de los discursos que tendrán lugarar a lo largo del concilio, esto se convierte en algo repetitivo. En este sentido, es obvio que no todos entendían lo mismo, pues mientras para Julio II la reforma debía consistir en el retorno a la norma o gobierno, que se había mantenido de forma tradicional, poniendo el acento en la restauración de la disciplina y de la moral, otros la entendían en una comprensión más acorde con las formas humanistas. Nelson H. Minnich llegará a afirmar que la preocupación del papa della Rovere no iba más allá de lo ya establecido ${ }^{3}$. Por su parte, León X entenderá la reforma en una triple dimensión: como restablecimiento de la paz entre los cristianos, en la reforma interna de la Iǵlesia y en la defensa de la fe, que comportaba tanto la batalla contra el turco como la extirpación de la herejía. Al mismo tiempo, es importante ver cómo este concilio propone una formulación canónica propia, que se concreta en el hecho de que los decretos sean redactados en forma de bulas.

3 Minnich, 1969, p. 165. 
Uno de los primeros núcleos de reforma conciliar es el que formarán los obispos pertenecientes a los reinos de Castilla y Aragón y que, bajo el auspicio de la corona, reflexionarán sobre la Iǵlesia y sus necesidades de transformación. Algoo que ya había estado muy presente en el sínodo de Burgoos de 1511, en el que se había preconizado la descentralización del poder a favor de los obispos, así como la oportunidad de someter a examen a aquellos que aspiraban a la colación de algún beneficio eclesiástico. Ambas medidas, si se hubieran llevado a efecto, habrían tenido también su repercusión directa sobre la predicación del pueblo, puesto que una selección mayor de los candidatos hubiera puesto freno a una de las grandes lacras de aquel momento histórico. Por su parte, Fernando el Católico, siguiendo la sensibilidad que se desarrollaba en la península ibérica, considerará la necesidad de reactivar el derecho e, incluso, que se precisase mejor la eclesiología. En esta dirección había influido, particularmente, el arzobispo de Sevilla e inquisidor general fray Diego de Deza, impulsor de la renovación de la teología promovida por los dominicos, en una clara vindicación del tomismo ${ }^{4}$ que tendrá luego, de la mano de Francisco de Vitoria y Domingo de Soto, su momento máximo de esplendor en la península.

El debate sobre la reforma había de promover a un mejor y más adecuado conocimiento teológico, pues después de las sesiones de debate en los concilios de Constanza y Basilea-Ferrara-Florencia, el tema del conciliarismo seguía siendo una seria preocupación, de manera especial, para los pontífices ${ }^{5}$. Por lo mismo, la reforma había de implicar también una más adecuada clarificación teológica.

Por desǵracia, el elemento por excelencia para la formación de los cristianos de a pie, la predicación, aunque había podido promover una adecuada reforma, estaba profundamente distante de las necesidades de instrucción y formación en la palabra de Dios que tenía el pueblo. Lo habitual era predicar a partir de las cuestiones de los maestros escolásticos, lo que resultaba ya anacrónico. Este será uno de los elementos fuertemente contestados por todos los intelectuales y pastores preocupados por la formación cristiana. Como ejemplo sirva el de la península itálica, donde los predicadores solían comenzar su alocución con la referencia a un sueño que habían tenido en la última noche. En dicha predicación podía estar presente la filosofía, las fábulas de Esopo, siendo frecuente que terminaran cantando «algunos versos de Francesco Petrarca o de Ludovico Ariosto» ${ }^{6}$. Con todo, lo más llamativo era la total ausencia de referencia a la Escritura o a los Evangelios. Eran, de hecho, los grandes ausentes. Se podía afirmar que, en dicha predicación primaba lo histriónico, buscando

4 Esto lo hace mediante su obra Diego de Deza, In defensione sancti Thomae...

5 Bédouelle, 2002, p. 33.

6 Campaǵnola, 2003, p. 22. 
deleitar al auditorio cuando no entretener a las gentes, olvidando totalmente su auténtica finalidad.

De esta manera, aunque el V Concilio de Letrán se mueve en un exceso de retórica, sí pondrá el acento en que la predicación era un elemento sustancial para la reforma de la Iǵlesia. Los padres conciliares entendían que la predicación podía terminar con los vicios y, por ello, mandan que los predicadores:

en el futuro se abstengan de aquellos comportamientos que han osado asumir en estos últimos tiempos... pues predicando no enseñan el camino del Señor, no explican el Evangelio como deberían, aunque lo intentan en todas partes con gran ruido. Pretenden convencer a la gente que crea en milagros ficticios, en nuevos y falsos vaticinios, así como otras cosas fútiles, similares a las fábulas de las abuelas, provocando así grave escándalo, sin tener cuenta de la autoridad, que desaprueba y rechaza todo esto ${ }^{7}$.

Al mismo tiempo promoverá que los candidatos al ministerio de la predicación fueran examinados oportunamente ${ }^{8} \mathrm{y}$, lo que es más importante, que predicasen la verdad evangélica y la Sagrada Escritura según la explicación, la interpretación y los comentarios de los doctores de la Iǵlesia o el dilatado uso aprobado y acogido hasta hoy... sin añadir nada que sea contrario y se separe de su sentido propio, muy al contrario, sigan siempre las opiniones que concuerdan con las palabras de la Sagrada Escritura y con las interpretaciones rectas incluidas de dichos doctores (p. 636).

Es interesante constatar que, aunque fuera de manera teórica, la palabra de Dios recuperaba el centro en la vida de la comunidad cristiana. A este fin, se recuperaba paulatinamente la conciencia de que los obispos, como administradores ordinarios de la enseñanza del pueblo, cuando no lo podían realizar directamente, estaban constreñidos a buscar varones idóneos, «poderosos en palabras y en obras», de tal suerte que hubiera una adecuada coherencia entre la palabra y el ejemplo. Por lo mismo, se entendía que no podía haber verdadera reforma si ambos elementos no convergían en la búsqueda de una vida más virtuosa.

7 Concilium Lateranense V, «Sessio XI. Circa modum praedicandi», p. 636.

8 «statuimus et ordinamus ut nullus tam clericus saecularis, quam cuiuiscumque etiam mendicatium ordinis regularis, aut quivis alius ad quem facultas praedicandi, tam de iure quam de consuetudine vel privilegio aut alias pertinet, ad huiusmodi officium exercendum admittatur, nis prius per superiorem suum respective diligenter examinatus, in qua re conscientiam ipsius superiori oneramus, ac morum honestate, aetate, doctrina, probitate, prudentia, et vitae exemplaritate ad illud aptus, et idoneus reperiatur, et hic, quocumque postea praedicaturus acesserit, de huiusmodi examine et idoneitate sua per literas authenticas seu alias sui examinatoris appobatorisque episcopis et aliis locorum ordinariis fidem legitime faciat». Concilium Lateranense V, p. 636. 
La norma canónica expresaba que los predicadores de oficio tenían la obligación de predicar, bajo pena de pecado mortal; por su parte, aquellos que lo eran por encargo, podían hacerlo si lo deseaban, y si no lo hacían, no cometían pecado mortal. Pero a todos se les exigía que,

según el precepto divino, explique y proclame el Evangelio a toda criatura, enseñe a rechazar el vicio y a practicar la virtud, y favorezca en todas partes la paz y el amor recíproco, tan recomendado por nuestro Redentor, que ninguno rasgue la vestidura inconsútil de Cristo (p. 637).

A los clérigos que se fueran a dedicar a la predicación, se le exigían tres requisitos formales: pureza de vida, conocimiento competente y que la autoridad le fuera otorgada por la Iglesia. Estas obligaciones estaban muy relacionadas con el fin último de la predicación, pues tenían que ganarse la voluntad de sus oyentes con el ejercicio de la humildad y, por medio del ejemplo y de la persuasión, ponerlos en el camino de la salvación. Pero lo cierto es que la predicación se vuelve una cuestión compleja como consecuencia del Renacimiento, ya que será difícil separar el efecto directo de éste en la práctica eclesial. Entendemos, en este sentido, que se vuelve hacia los modelos clásicos de la retórica y la elocuencia, que tenían una finalidad diversa a la que le correspondía propiamente a la predicación evangélica. Con ello se quería frenar el progresivo deterioro que venía ya de lejos. Los humanistas serán críticos con la ignorancia y la falta de formas de los predicadores pero sin llegar a reclamar la adecuada virtud que había de acompañarles. Las propuestas y condiciones marcadas en el aula conciliar irán también orientadas hacia el cuidado de la persona del predicador, lo que iba en relación al hecho de que la mayoría de los oradores que intervendrán en el aula contaban con experiencia pastoral concreta, al tiempo de ser conocidos por sus cualidades oratorias, lo que también servía como elemento paradiǵmático en el aula conciliar. El problema era la difícil síntesis que se había de hacer entre teoría y praxis.

Los cambios relativos a la predicación están también en relación directa al concepto teológico de la misma, y cómo esta servía al esquema de la salvación. Se recupera así la idea de que la predicación es una parte fundamental del culto dominical. Pero después de la experiencia dramática de fray Girolamo Savonarola, Roma considerará también una prioridad controlar la predicación, frenando todo tipo de profecías que auguraban reformas súbitas y, con frecuencia, vinculadas con el final del mundo. El dominico había propuesto una reforma de la civitas christiana ${ }^{9}$. Savonarola, en concreto, había señalado las cuestiones fundamentales; aquellas que no podían ser olvidadas, aunque lo hiciera en un tono

9 Savonarola, De veritate prophetica [lib. VI], pp. 329-342. 
apocalíptico. El acento lo había puesto en la necesidad y fuerza del buen ejemplo, que era lo que podía provocar el cambio auténtico.

De esta manera, se va perfilando la búsqueda de una predicación más depurada, reconociendo su carácter eficaz y especialmente oportuno. En esa línea se ubica, en el marco conciliar, la intervención del laico, Gianfrancesco Pico della Mirandola, el 19 de diciembre de 1516. Este discípulo de Savonarola, y sobrino del príncipe de la concordia, se dirigirá al auditorio con una disertación de reforma -en un tono marcadamente conciliador, procurando distanciarse de los excesos-. Pondrá de relieve que, para superar la ignorancia y la incredulidad de las gentes, era necesaria una vuelta a la formación clásica, pero que fuera acompasada por un verdadero cambio de vida. Para ello el clero tenía que dedicarse seriamente al estudio, particularmente de la Sagrada Escritura, que debía ser purgada de los errores que se habían ido superponiendo en los sucesivos traslados. Al mismo tiempo, los clérigos debían cuidar el oficio y la liturǵia, llevando una vida digna ${ }^{10}$. Con estas «herramientas» se podía recuperar la pietas, que representaba el ideal de vida cristiana y, al mismo tiempo, la paideia, que refería al ideal educativo propuesto. Sus palabras remiten a una reforma donde se recuperan esos dos principios, incidiendo en el ejemplo de vida ${ }^{11}$ :

No pido que [los sacerdotes] se den golpes de pecho con una piedra como Jerónimo, pero tampoco que adornen las prostitutas con preciosos collares, ni su calzado con gemas del Hydaspes. Y mucho menos quisiera imponerles que se habitúen a los ayunos de Hilarión, pero que no imiten o superen la mesa de los sibaritas. [...] Recomiendo la moderación [...]. No se crean, que cuando les amonesto a ser generosos en el dar, que yo quiera obligarles a imitar en todo a aquel espléndido y famosísimo gesto de Martín, que dividió la capa para vestir un pobre mendigo que tiritaba de frío. Pero quisiera que aquellos que tienen dinero en abundancia, fuesen inducidos, por el ejemplo de Martín, a vestir al desnudo, más que cubrir con paños de púrpura sus caballos ${ }^{12}$.

Pero una de las aportaciones más valientes y proféticas de reforma no vendrá del aula conciliar. Es preciso también mirar fuera de las sesiones oficiales del concilio, de la mano de los eremitas camaldulenses venecianos Paolo Giustiniani y Pietro Quirini. El Libellus ad Leonem $X^{13}$ es un extenso memorial de cien columnas que estaba avalado por años de estudio y experiencia. Estos eruditos humanistas fueron capaces de ofrecer un juicio lúcido sobre la situación de la Iglesia. Así, al tiempo que denunciaban la avaricia de los príncipes, se referían también a

\footnotetext{
${ }^{10}$ Minnich, 1969, p. 203.

${ }^{11}$ Schmitt, 1970, p. 170.

12 Pico della Mirandola, De reformandis moribus oratio. Tomado de Mezzadri, 2001, p. 105.

13 Giustiniani y Quirini, 2016.
} 
la iǵnorancia del pueblo (col. 670). Sus aportaciones se encuentran sustentadas en la Escritura y los Padres, mostrándose distantes de las intrigas y ambiciones de los eclesiásticos de aquel tiempo ${ }^{14}$. De esta manera, la reforma se presentaba también como la búsqueda y recuperación del ideal perdido, pero para ello era necesario que el papa volviera a sus funciones, que no eran otras que el gobierno y el servicio apostólico.

Considerarán, al mismo tiempo, que un camino necesario era erradicar la ignnorancia del clero por medio de la formación, poniendo el acento en el estudio de la Sagrada Escritura, los Padres y los cánones conciliares y las decretales de los papas ${ }^{15}$. Entendían que nadie podía ser admitido a las órdenes sagradas, a menos que fuera capaz de leerlas y comprenderlas adecuadamente. De igual manera, para facilitar la adecuada formación del pueblo, debían ser traducidos a las lenguas vernáculas los artículos de fe, las epístolas y los evangelios. Este había de ser el sustrato adecuado para la predicación y los sermones. La formación cristiana, al mismo tiempo, debía ayudar a superar las supersticiones, ya que el pueblo comprendiendo las Escrituras, los oficios divinos y los cánones de la Iǵlesia tendría un adecuado criterio de vida y elección (cols. 683).

\section{Los albores de una nueva sensibilidad}

El surgimiento de una sensibilidad de reforma, como hemos señalado, ponía de relieve la importancia de la predicación. A su lado iba aparejada toda una serie de elementos que cobran una importancia singular en autores de la

${ }^{14}$ Minnich, 1969, pp. 222-223.

15 «Millia multa reliǵiosorum hominum invenies, qui neque legere quidem, neque scribere mediocriter sciunt. In omni autem tam numerosa Religiosorum multitudine vix duo ex centum, aut decem [676] e mille reperies, qui tantum Latinae linguae addiscerint, ut quae Latino sermone conscripta cottidie in Ecclesiis legunt, plane valeant intellegere; ex his vero, qui intellegunt, paucos admodum invenies, qui ulterius ad aliquam disciplinarum, atque scientiarum coǵnitionem progressi sint; ex paucissimis vero illis, qui litterarum studiis incumbere quoquo modo videntur, rarus quippe est, qui non Poetarum potius mendacia, aut Philosophorum impietatem, quam Christianam pietatem amplexus sit; ex rarissimis vero illis, qui veram, solamque Philosophiam, Christianam Disciplinam sequuntur, vix unum, aut alterum invenies, qui non inanissima recentiorum Scriptorum argumenta, simultatum sane, odiorumque irritamenta, potius quam Sacrarum Scripturarum, antiquaque Patrum documenta sectetur; qui non inanibus quaestionibus, quae ad nihilum quidem utiles sunt, potius quam Sanctorum Evangeliorum lectionibus occupetur; qui denique non illam potius vanam, quae inflat, quae extollit, disputativam disciplinam, quam illam sanctam, puram, castamque Sacrarum Scripturarum, quae inflammat, et humiliat, doctrinam sequatur. Et si unum, aut alterum huiuscemodi reperire fortasse poteris, numquid tantum profecisse ullum omnino invenies, ut in tota Ecclesia Dei hoc saeculo aliquem unum habeas, quem possis cum antiquioribus illis Patribus, quibus Graeca, et Latina Ecclesia praeteritis saeculis abundavit, comparare». Giustiniani y Quirini, 2016, cols. 675-676. 
península ibérica, en las primeras décadas del siǵlo XVI. Es el caso de Antonio de Nebrija o de Pedro Ciruelo, autores en los que encontramos una preocupación por cuestiones afines o paralelas como es la liturgia y su adecuada renovación, y que, lógicamente, incidían también en el ars praedicandi. En este sentido, aunque Nebrija no tiene una preocupación explícita por el tema, posiblemente por el hecho de no ser clérigo, sí tiene una inquietud seria como filólogo -particularmente como latinista- pues le atormenta que aquello que había de ser predicado no fuera filológicamente correcto y, también, adecuado métricamente. En este sentido, se trataba de cultivar las letras humanas para ponerlas al servicio de la palabra de Dios.

No era el único que estaba preocupado por elevar la formación del clero, pues en esa línea se encontraban también Cisneros, Talavera, Rodríguez de Fonseca, Villaescusa, e, incluso, Arnaldo Guillén de Brocar. Estos, precisamente, «le pedían que corrigiese y comentase los libros eclesiásticos y los poetas cristianos... para la mejor formación de sus ministros» ${ }^{16}$.

Él mismo colaborará con la corrección y publicación, en 1541, de la obra Hymnorum recognitio, algo que ya había hecho anteriormente. Como señala Olmedo, los ejemplares de la misma suelen estar encuadernados con otras obras menores (pp. 145-147). Su tarea «se redujo a reparar el texto y a corregir la puntuación y la ortografía» (p. 161). Se trataba de diversos libros, que comprendían oraciones, diversas homilías de autores sobre el Evangelio y, por último, los segmenta de las cartas de Pablo, Pedro, Santiago, Juan y otros profetas. Su aportación consistió en depurar los textos de errores y hacer que la lengua resultase más elegante. Algoo, por otra parte, a lo que dedicará gran parte de su madurez intelectual.

Su hijo, Sancho Nebrija, nos da las claves de la finalidad de este tipo de trabajos del gramático, en los que él había colaborado también. La intención era precisa y cabal: «representar tan al vivo la humildad cristiana y enseñar al pueblo en su mismo lenguaje las verdades de la fe» ${ }^{17}$. Para ello, se trataba de ofrecer modelos al lector, en el convencimiento de que dichos textos seguían siendo válidos y tenían algo que decir al lector ${ }^{18}$. No se trataba de homilías de un único autor, sino que se buscaba también que «con la variedad» fuera «mayor el gusto y el provecho de los lectores» (p. 162). Como era de esperar, el paradigma por excelencia

${ }_{16}$ Olmedo, 1942, p. 159.

17 Prefacio a Homiliae per diversos autores in evangelia, 1543. Tomado de Olmedo, 1942, p. 162.

18 «Cuando sus autores pronunciaron esos discursos, los auditorios los oían con extraordinaria atención y admiración y a veces prorrumpían en grandes aplausos, porque era tal el gusto que sentían, y se les quedaban tan grabadas aquellas cosas en el alma, como se veía por el efecto, que no creo yo ni Demóstenes ni Cicerón tuvieron más gracia para deleitar ni más fuerza para persuadir». Olmedo, 1942, p. 162. 
es el mismo Cristo, que se refleja en esas homilías, "cuya voz no puede menos de sonar en los oídos de los cristianos, cualesquiera sean las palabras en que las envuelva el predicador» (p. 162).

Aunque esto puede ser visto simplemente como una cuestión técnica, no hay duda de que, en razón de la importancia que lo reliǵioso tiene en este momento, Nebrija está colaborando conscientemente para dotar a los predicadores de herramientas adecuadas para su tarea. Así lo había dejado expresado él, como señala Víctor Pastor, tomando las palabras del libro II, De doctrina christiana:

Ayuda muchísimo ver y comparar (collatis) entre sí muchos códices, siempre que no haya falsedad. Porque lo primero que tienen que hacer los que desean conocer las Escrituras Sagradas es enmendar (emendatis) cuidadosamente los manuscritos (codices) para que los que no están corregidos se conformen con los que lo están, porque si no, ¿cómo vamos a saber lo que es o no es de fe, lo que nos está mandado y lo que nos está prohibido? La regla para esto la da el mismo Santo Doctor allí mismo y en muchos otros lugares, en este mismo libro segundo De doctrina christiana y en el tercero. Y también San Jerónimo en todos sus prólogos, epístolas y comentarios, y es la que nos enseñaron los antiguos y santísimos doctores: que siempre que en el Nuevo Testamento haya alguna diversidad entre los libros latinos, recurramos a los griegos; y siempre que en el Antiguo Testamento difieran los códices latinos entre sí o con los griegos, recurramos a los hebreos; o sea, que en las dudas siempre hay que recurrir a la lengua precedente ${ }^{19}$.

No tiene menor importancia el hecho de que Nebrija, desde 1495, tuviera claro que quería «consumir el tiempo que nos queda de vida en el estudio de las Sagradas Escrituras» (p. 82), algo que volverá a afirmar en 1520, cuando escriba a su discípulo Enrique de $\mathrm{Hamusco}^{20}$. En esta preocupación se enmarcaría también cierto rechazo del escolasticismo presente en la academia y en la predicación. En este orden de cosas, y ante los ataques permanentes que sufre de los teólogos escolásticos, siente la necesidad de defenderse, mostrando que él no es un intruso:

Me llaman temerario, porque con solo el Arte de la Gramática me meto por todas las demás artes y disciplinas, no como tránsfuga, sino como explorador y centinela, para ver lo que hace cada uno en su profesión ${ }^{21}$.

\footnotetext{
19 Pastor, 2015, pp. 84-85.

${ }^{20}$ «el tiempo que me quede de vida, imitándote en todo, entregaré mis desvelos a las Sagradas Letras. Mientras tanto, publica tu obra contando con Buenos augurios y no nos prives de tan preciado regalo. Vale ex Compluto... 4 de mayo de 1520». Pastor, 2015, p. 95.

21 Pastor, 2015, p. 92.
} 
Por su parte, Pedro Ciruelo había publicado, en 1528, la Expositio libri missalis peregregia que Pedro M. Cátedra calificará de «medieval» ${ }^{22}$, aunque la apreciación no la consideramos muy certera. Ciruelo ubica el arte y el ejercicio de la predicación en el ámbito de la cura animarum, considerándolo homólogo de la liturgía y la administración de los sacramentos ${ }^{23}$. Ciruelo ordena una explicación doctrinal y ascética, no solo del misal, sino también de las horas canónicas y del mismo salmo 118. Con análoga intención había escrito una serie de trabajos de corte teológico, que también manifestaban la línea de preocupaciones apostólicas que se encuentran en otros maestros de Alcalá. Por una parte, se trataría de aquellas que se relacionaban directamente con la Saǵrada Escritura, la espiritualidad y el sacramento de la reconciliación y, por la otra, con la formación del clero, algo que no era una inquietud frecuente entre los maestros, que seguían preocupados en «mover las sentencias». A la primera parte corresponden algunas obras inéditas como la Cuádruple versión del Génesis, que se encuentran ubicadas en su etapa segoviana, así como algúna traducción de la Escritura. En la misma línea se sitúa su Confesionario ${ }^{24}$, que contará con un número nada desdeñable de ediciones, así como su Reprobación de las supersticiones y sus Contemplaciones sobre los misterios de la Pasión, obras que se ubican en la espiritualidad renacentista castellana.

La publicación conjunta de esta obra está ofreciendo un material al predicador, así como a todo clérigo que se vaya a dedicar al apostolado. De esta manera, Ciruelo ayudaba a que los clérigos ordenados in sacris tuvieran una mayor y más eficaz vivencia de su ministerio. Ciruelo estaba convencido de que la manera como fuera vivido tenía una repercusión directa en el pueblo y, por lo mismo, se colocaba él también en la línea de los eclesiásticos sensibles por la reforma de la Iǵlesia. Por ello era preciso un conocimiento más profundo de aquello que se celebraba, por qué y cómo se había de celebrar, superando el límite de un clero burdo e inculto. Era, por tanto, una preocupación teológica, ascética y pastoral, ante un clero no suficientemente juicioso ante los misterios a que era convocado. Ya en el prólogo de la obra expresa cuál es la intención y finalidad de la misma. Pedro Ciruelo afirma que la liturgia ha de reflejar, relatar y hacer viva la historia salutis.

Entiende que la liturǵia conmemora los múltiples y diversos acontecimientos del pueblo de Dios, dentro de la historia del hombre. Por lo mismo, las diversas partes de la misa han de ayudar a hacerlo verificable, evidenciando ante los

22 Cátedra, 1994, p. 132.

${ }^{23}$ Como hemos señalado, no es que fuera muy oriǵinal pues esta propuesta tenía una vinculación con Gabriel Biel, quien tenía una honda preocupación pastoral, que se refleja en sus sermones y comentarios al canon de la misa, así como en la importancia concedida a la palabra de Dios, unida a la predicación. Acerca de su fiǵura, Oberman, 2001; Biel, 2001.

${ }^{24}$ La primera edición es de 1524. 
hombres el sentido lineal y teológico de la historia de la salvación ${ }^{25}$. Pero hay que tener en cuenta que estas iniciativas, de corte académico e intelectual, no agotan sus preocupaciones apostólicas, sino que estas tendrán también un marco más práctico y concreto; por lo mismo, como refiere García Hernán, Ciruelo dirige y acompaña a un grupo de mujeres, de igual manera que harán luego el Maestro Ávila o el mismo Iǵnacio de Loyola ${ }^{26}$. En este sentido, la reforma de la Iǵlesia tenía que llevarse a cabo utilizando todas las herramientas a su alcance y, también, dirigiéndola a todos los sectores de la sociedad.

Cuando Ciruelo escribe estas obras, se encuentra ya enseñando en Alcalá. Para este momento, su pensamiento ha alcanzado ya su madurez. Se trata de un hombre que se muestra como un polímata, pero que sigue dando particular importancia a la formación de aquellos que luego se van a dedicar al ministerio ordenado y, particularmente, al de la predicación. Esta sensibilidad, insistimos, no parece tan medieval, pues aunque pueda no ser original en su planteamiento y discurso, sí se está trasparentando una nueva sensibilidad; aquella que está presente en los comienzos de la Modernidad, donde la preocupación por la transmisión de la fe se convierte en algo vivo e intenso. Ciruelo remite a una experiencia personal y propia, en la que intenta responder a problemas concretos con los que él se ha tenido que enfrentar. Tampoco esto parece muy medieval, sin llegar obviamente a tener el grado de innovación o sutileza que tendrán las aportaciones que pueda hacer después Erasmo, en este mismo horizonte.

Se muestra ansioso por la acción apostólica -algo característico de la Universidad de Alcalá-, aquella impronta que Cisneros logrará inculcar en docentes y discentes de las primeras décadas. Unos activos eficaces, que se infiltrarán en todas las estructuras de la sociedad de su tiempo logrando una vida más virtuosa. Precisamente por ello la preocupación de Ciruelo no se dirige, de manera exclusiva, en la línea del renacimiento bíblico de la época, sino que hace referencia también al papel que esta tiene de cara al pueblo de Dios. Siente y constata la necesidad de formar a los pastores y al pueblo. Aun siendo un escolástico de nuevo talante, tal y como será luego Francisco de Vitoria, plantea una pietas litterata de claro sabor intimista, que se aleja de formas ceremoniales externas y de una religiosidad institucionalizada ${ }^{27}$, buscando esa recuperación del mundo interior. Ahí se explica y tiene pleno sentido la publicación de unas obras, estrechamente

25 «Erunt autem haec nostra principia, quibus totius edificio structura substentatur, verissima et ab omnibus doctis fidelibus concesse. Et eis bene intellectis apparebit statit intentio nostri operis principalis. Et inde concipietur spes secure perveniendi ad finem optatum. Hoc est ad verum et litteralem sensum libri missalis et aliorum officiorum Ecclesiae Dei». Ciruelo, Expositio libri missalis, fol. $4 \mathrm{v}, \S .6$.

${ }^{26}$ García Hernán, 2013, p. 166.

27 Álvarez Turienzo, 1986, p. 50. 
vinculadas entre sí y con una finalidad común; atendiendo a la manera de celebrar, el estilo de predicación, la cualidad de la memorización y en qué celebraciones incidir más. Elementos que el predicador debía manejar adecuadamente, de tal suerte que fuera capaz de conectar con el pueblo, con su sensibilidad y, también, con sus necesidades.

Para esto, no será suficiente con tener una idea, sino que será preciso contar también con los medios oportunos para que esta se pueda difundir y multiplicar. Precisamente por ello López Muñoz afirmará que

no son la misma cosa el retórico, el orador y el predicador. El primero, reflexiona y enseña cómo construir discursos persuasivos; el segundo, interactúa con un auditorio para transmitir una idea; el tercero es, como caso específico del anterior, el que se dedica a difundir contenidos de la fe ${ }^{28}$.

En este sentido Ciruelo colabora a este fin desde los dos primeros. Pero no se puede tampoco perder de vista que, en lo que se refiere a la predicación, se da también todo un talante singular, que vincula el ejercicio de la misma directamente con Dios, por lo que esta dependería más de esa dirección que de una concreta manualística, como sucederá más tarde. Precisamente por ello trabajos como los de Ciruelo o Nebrija se volverán tan significativos, ya que facilitaban las herramientas oportunas para abordar un trabajo coherente y válido.

Por suerte la retórica española será más tardía, por lo que los autores podrán ir experimentando y ofreciendo herramientas, algo a lo que no se le ha dado la importancia requerida, por no tener la forma concreta de un ars, ya fuera medieval o moderna. Este tema, por lo mismo, requiere de mayor atención, poniendo de relieve como la reforma de la predicación castellana tiene un carácter marcadamente práctico, donde los fines ocupan un papel preponderante frente a los medios para la misma. En este sentido, primero se desarrollará una praxis viva de predicación y, posteriormente, los autores elaborarán y formularán toda una manualística, que incluso mirará a los parámetros clásicos de la retórica y la elocuencia.

Se podría decir que, en los entornos católicos, será frecuente asumir y afrontar la necesidad de evangelizar, pero sin contar con un adecuado adiestramiento retórico, que es suplido por otros ritos y que, posteriormente, se formulará con más precisión. Con todo, incluso los predicadores más sobresalientes de esta época se refugiarán en el método y contenido de la dialéctica.

Aunque no contamos con el espacio adecuado para afrontarlo, no queremos pasar por alto que, en 1529, Melanchton publica también su De officiis

\footnotetext{
${ }^{28}$ López Muñoz, 2000, pp. 336-337.
} 
concionatoris $^{29}$, que se adelanta unos años a la propuesta que luego hará Erasmo en su Ecclesiastes. Esta aportación, como afirma O’Malley, «aunque no expresaba enteramente su pensamiento definitivo» ${ }^{30}$, será fundamental, no solo para el entorno protestante, sino que supondrá dotar a la retórica de un papel determinante, que está vinculado con aquel que le corresponde en la formación religiosa del pueblo. Como afirma Campos Vargas -tomándolo de palabras de Dyck- el predicador luterano debía ser un retórico y un dialéctico, lo que implicaba que su tarea era la de enseñar y exhortar ${ }^{31}$.

Algo que, precisamente, el praeceptor Germaniae evidencia al cuestionar la división tripartita propuesta por Aristóteles. Este, al referirse a los géneros del discurso, planteaba los siguientes: el deliberativo, que se refería al uso por el pueblo en sus discusiones; el forense, destinado a la esfera judicial; y el epidíptico, usado en el mundo del espectáculo. Melanchton añadirá ahora el didascalico u homilético, con esa función precisa y propia ${ }^{32}$. O'Malley explicando esta singular aportación afirmará que «el didascalicum y el epitrepticum son bastante más importantes que el pareneticum, porque tratan de la fe, mientras que el pareneticum trata de la acción» ${ }^{33}$.

Esta aportación es particularmente interesante, en su preocupación por la reforma, pues muestra ya claramente que se trata de un texto humanista, propio de la Modernidad, en el que se abandonan los parámetros escolásticos medievales. Melanchton ya no habla de sermo, sino de concio ${ }^{34}$. El detalle resulta particularmente significativo, ya que se abandona un intercambio, como conversación, proponiendo un discurso breve que va dirigido a los fieles y, por lo mismo, a sus necesidades reliǵiosas. La homilía tiene una pretensión precisa y firme, que él identifica claramente: enseñar.

Como ha señalado Carmen Grace «el término concionatorio se refería a la teoría y a la praxis de la predicación específicamente renacentista que se apoyaba en la retórica como herramienta de persuasión» ${ }^{35}$. En este sentido, para

\footnotetext{
${ }^{29}$ Melanchton, 1929.

${ }^{30}$ O'Malley, 1999, p. 287.

${ }^{31}$ Campos, 2009, p. 221.

${ }^{32}$ A este respecto, O’Malley afirma: «En el De officiis, Melanchton define su teoría sobre la predicación emplenado tres genera: el didascalicum, que enseña la verdadera doctrina, el epitrepticum, que exhorta a la fe, el paraeneticum, que exhorta a las buenas costumbres morales. El epitrepticum y el paraeneticum se consideran exhortaciones, adaptaciones del clásico genus deliberativum». O’Malley, 1999, pp. 287-288.

${ }^{33}$ O'Malley, 1983, p. 228.

${ }^{34}$ Resulta sugerente recordar aquí la Concio De puero Iesu, de Erasmo, homilía pensada para los niños. Algo que había expresado también en su Pietas puerilis, donde muestra la necesidad de coherencia de vida en el predicador.

35 Grace, 2016, p. 967.
} 
Melanchton y los reformadores, la predicación se convertirá en el recurso más común y eficaz. Precisamente por ello, O’Malley afirmará que

el genus didascalicum fue el que llamó la atención de los contemporáneos de Melanchton y de generaciones sucesivas. En ese genus él continúa con una atención a la doctrina proporcionalmente y dialécticamente articulada, que seguramente sin intención, recordaba los sermones temáticos de los escolásticos ${ }^{36}$.

Posteriormente, desde la mirada católica se tenderá también a una retórica defensiva y combativa, pero quizás con menor elegancia de la que había propuesto el reformador humanista.

\section{El Ecclesiastes de Erasmo de Róterdam}

No hay duda que uno de los autores más influyentes de esta época es Erasmo de Róterdam, intelectual que no muestra propiamente interés por la oratoria, sino que su atención va diriǵida fundamentalmente hacia la predicación del Evangelio $^{37}$. Si le interesa la renovación de la retórica es porque la predicación había llegado a un estado deplorable. Era necesario poner remedio a esta situación, por lo que había que buscar los medios más oportunos para acercar al pueblo el mensaje del Evangelio.

No deja de ser llamativo que su última obra sea precisamente dedicada a la predicación, el Ecclesiastes, publicada en 1535. Obra que algún autor ha considerado como su pensamiento definitivo sobre esta temática ${ }^{38}$, pero que necesariamente se completaría también con otros trabajos como las Paráfrasis, sus concio y otras píldoras que va dejando a lo largo de toda su obra ${ }^{39}$. Es obvio que el Ecclesiastes puede ser considerada como una obra de madurez, donde su autor se preocupa porque se obtengan buenos predicadores, capaces de enseñar al pueblo, y no meros oradores ${ }^{40}$. De esta manera, la obra no tiene como finalidad la retórica sino la homilética, aunque sí adaptará los principios y las técnicas de los retóricos a la función propia y singular del predicador.

El manuscrito se demora durante años en su escritorio. Era fruto de una idea que le había sugerido, en 1519, John Becar de Borseleu, pero que solo concluirá

${ }^{36}$ O’Malley, 1999, p. 288.

37 Cátedra, 1994, p. 135.

${ }^{38}$ Kleinhaus, 1968, p. 3.

${ }^{39}$ Es importante, a este respecto, no perder de vista, como ya señalara M. Bataillon, que el mismo san Juan de Ávila había recomendado, en sus primeros años de apostolado en Andalucía, el uso de las paráfrasis de Erasmo. Véase Bataillon, 2000, p. 157.

${ }^{40}$ O'Malley, 1999, p. 289. 
al final de sus días por la insistencia de sus amigos y admiradores ${ }^{41}$. Quizás había que pensar también que Erasmo no terminaba de tener todas las ideas claras al respecto de la misma.

Como suele ser frecuente en sus obras, si miramos a quién va dedicada, podemos intuir y precisar mejor cuál es su intención. En el presente caso se trata del obispo Christoph von Stadion, hombre profundamente humanista y sensible a la reforma de la Iǵlesia y, por lo mismo, interesado también en la predicación. Allí mismo, Erasmo evoca la figura del difunto obispo de Rochester, John Fischer, que igualmente había sido un pastor profundamente sensible ante estos temas. A él hubiera dedicado la obra si Enrique VIII no lo hubiera ejecutado. Para Erasmo reforma y predicación son una misma cosa y no pueden ser entendidas por separado si se quiere alcanzar una Iǵlesia más auténtica. Para él la tarea encomendada al predicador en la sociedad resulta de tanta trascendencia como la del soberano o la del obispo, por lo que es preciso dedicarle la atención necesaria, tanto mirando a su formación específica como a la selección de los candidatos. Y, en este sentido, el predicador por excelencia es el obispo, que tiene el deber de predicar a sus feligreses, pero también tiene la responsabilidad de seleccionar hombres que hagan este ministerio con dedicación y solicitud. O’Malley afirmará que la tarea del predicador es «explicar y enseñar los misterios de la Escritura, la 'filosofía' de Cristo»" ${ }^{42}$.

A diferencia de otras temáticas de índole más pedagógica Erasmo no es muy preciso, aunque sí muestra una honda y seria preocupación por el tema. El ensayo está compuesto por unas mil columnas, donde las frecuentes referencias a la predicación de su tiempo y las anécdotas sobre la oratoria en el púlpito nos sirven también como indicaciones para tomar el pulso ${ }^{43}$. De todos modos, ya en la carta 1211, escrita a Justus Jonas, había presentado la figura del franciscano observante Jean Vitrier ${ }^{44}$ como paradigma del predicador:

Él [Vitrier], por el contrario, mediante una especie de flujo continuo del sermón, unía la epístola con el pasaje evangélico de manera que el oyente volvía a casa más instruido y más inflamado de un deseo de [vida] piadosa... Un increíble ardor poseía a [este] para llevar a los mortales a la pura filosofía de Cristo... su

${ }^{41}$ John O'Malley insistía que a esta obra no se le ha dado la importancia que le corresponde, pues a Erasmo se le ha considerado fundamentalmente como un pensador religioso, pero como si él no tuviera una preocupación auténtica por la teología y la piedad. Véase O’Malley, 1985, p. 2.

42 O’Malley, 1999, p. 289.

${ }^{43}$ Erasmus Roterodamus, «Ecelesiastes...», vol. V, cols. 796-1100. De ahora en adelante la citamos como es habitual: $L B \mathrm{~V}$ y la columna que corresponda.

44 Acerca del mismo, véase Vitrier, 1971. 
vida y su enseñanza eran una fuente de extraordinaria piedad evangélica... siguió él mismo: enseñando, consolando, exhortando... la chispa de su enseñanza aún sigue viva en muchos corazones ${ }^{45}$.

No es ingenuo que comience su obra con una definición sobre qué es la Iǵlesia, que él concibe como asamblea general del pueblo. Entiende la sociedad como un todo, donde ocupa también un papel importante la naturaleza espiritual de la Iglesia, que supone la aceptación de la doctrina de Cristo. Y, en este sentido, mostrando esa imagen como cuerpo, se entiende que, igual que en la corte se buscan las personas mejor capacitadas para las distintas tareas, también los predicadores han de ser seleccionados de manera análoga. Dicha misión corresponde a los obispos, a los que les propone un programa de estudios bien delineado, una biblioteca selecta al efecto y una tríada del obispo ideal para dicho fin, en la que se encuentran Warham, Fisher y el mismo Gregorio Magno ${ }^{46}$.

A Erasmo no solo le interesa cómo se han de formar los candidatos, sino que su preocupación incide también sobre aquellos a quienes corresponde la selección, pues sin ese espacio de verificación no se logrará la ansiada reforma de la Iǵlesia. Utiliza, como fuentes para sostener su pensamiento, el De doctrina christiana de san Agustín y la Institutio oratoria, de Quintiliano ${ }^{47}$, entroncando así con las obras más clásicas en retórica y homilética. Erasmo mostrará la importancia del predicador en la comunidad, lo que incluye una discusión sobre el valor del oficio, así como un diseño del marco general en el que ha de desempeñar su función propia. Él, como orador sagrado, tiene la responsabilidad de ser intérprete de la palabra de Dios. Y, siguiendo el ejemplo del Hiponense, no se detiene solo en la retórica sacra, sino que muestra también interés por la hermenéutica de la Escritura. Por eso se preguntará «cuáles son los preceptos de la retórica, la lógica y los teólogos que se han de acomodar para uso del predicador» ${ }^{48}$. No hay duda de que se trata de poner en valor esas herramientas que han de estar en las manos del orador sagrado, para lograr que el pueblo sea virtuoso.

A este respecto, no solo resulta necesario conocer su doctrina, sino cómo esta es justificada en un marco teológico total. Precisamente por ello le preocupa la formación que habían de recibir los predicadores, pues entiende que se habían de formar en escuelas orientadas a este fin y no tanto a producir teólogos. Esta

${ }^{45}$ Opus epistolarum, 1922, n. 1211, pp. 509, 511, 513, 514. Nos valemos de una traducción de Víctor Pastor que nos ha facilitado muy amablemente.

${ }^{46} \mathrm{LB}$ V, cols. 125-130, 810-812.

47 O'Malley, 1999, p. 289; Tubau, 2009, pp. 31-32.

48 «quae sunt in praeceptionibus rhetorum, dialecticorum, ac theologorum, ad usum concionandi accomodamus». $L B \mathrm{~V}$, cols. 767-768. 
preocupación era consecuente con su interés permanente por la educación y, de manera particular, por el papel del educador. De esta manera, igual que se había preocupado por editar obras que sirvieran para la educación y comentar los tratados más importantes, ahora proponía un itinerario también para la formación de los predicadores. En su comprensión se trataba de una aportación más a la reforma de la Iǵlesia, que no podía llevarse a cabo solo en cuestiones aisladas, sino que requería de un programa coherente y cohesionado.

Dicha formación, además, entendía que debía comenzar lo más pronto posible, pues no era una cuestión que se refiriera solo a la adquisición de unos conocimientos teóricos y de una elocuencia, sino que requería también moldear el carácter. Esto suponía ya de entrada que, para dicha tarea, no valía cualquiera sino que se requería una selección y una búsqueda atenta y meticulosa de los candidatos.

En relación a la misma, intenta ser lo más preciso, en lo que se refiere al contenido y al método de educativo. El futuro predicador debía aprehender diversas artes, pero particularmente gramática, retórica y dialéctica. Y, en este sentido, por ejemplo, la gramática sería particularmente adecuada para poder comprender las alegorías que se encuentran en las Escrituras. Esto lo acompaña también de una lista de autores eclesiásticos indispensables en dicha formación y con los que los predicadores tendrían que estar bien familiarizados. Entre estos, los Padres ocupan un papel especialmente preponderante.

Todo ello obedecía a la tarea encomendada al predicador, que no era otra que interpretar las Escrituras y, al mismo tiempo, proclamar su mensaje. Y aquí, coincide abiertamente con otras propuestas muy distantes geográficamente como las del Maestro Ávila, cuando propone que no se trata de un mero aprendizaje de libros, sino que es preciso ir asumiendo, podríamos decir hoy, una mistagogía, pues los predicadores debían escuchar y seguir modelos vivos de buena predicación. Debían mezclarse con aquellos que hablaban bien, pues debían llegar a un adecuado dominio de la misma lengua, para así persuadir por medio del ejemplo vivo ${ }^{49}$. Pero, además, el orador debía también amar aquello que enseñaba, a fin de encender ese amor en su auditorio. Era la elocuencia la que había de mover a la piedad ${ }^{50}$. La manera de expresarlo resulta irrefutable: «Qualis est sermo noster talis est spiritus noster ${ }^{51}$. Unas líneas más adelante lo expresa de manera elocuente: «Cualquiera que sea la cualidad del corazón de un hombre, así será también su discurso» ${ }^{52}$.

Por ello, aunque no solo, le desaǵradaban los predicadores pomposos, que elaboraban sermones repletos de sutilezas escolásticas. Así, en el Elogio de la locura

\footnotetext{
${ }^{49} L B \mathrm{~V}$, cols. 857-859, 877-887.

${ }^{50}$ Weiss, 1974, p. 93.

${ }^{51} \mathrm{LB} \mathrm{V}$, col. 772 .

52 «Qualecumque est cor hominis, tali est oratio», $L B \mathrm{~V}$, col. 773.
} 
censuraba la pedantería y lo histriónico de los que él denomina «enamorados de la retórica» ${ }^{53}$. A este respecto, pone el ejemplo de predicadores que usan los elementos de la gramática para explicar la Trinidad, o el de aquel predicador que encuentra en la respuesta de María al ángel, una oportunidad para exhortar sobre la importancia de las indulgencias.

Como pondrá de manifiesto O’Malley, «mientras el sermón medieval daba importancia a docere, a expensas de movere y delectare, la nueva plática demostrativa coordinaba con más efectividad enseñanza y persuasión ${ }^{54}$, pero no se quedaba solo en exhortar, sino que se trataba también de elevar la virtud. Erasmo quería poner de relieve que al enseñar se podría instruir o persuadir a las gentes, pero el rol del predicador era principalmente el de persuadir, pero esto tenía que lograrlo por medio de un discurso honesto y virtuoso. A este fin le dará un valor significativo a la elocuencia, que no podía consistir en una mera proclamación de la voluntad de Dios, sino que tenía que ser una llamada veraz a vivir conforme al ideal cristiano, que no era otro que el ejemplo del mismo Cristo. Estaba afirmando que nadie puede ser conmovido o subyugado por aquello que no es capaz de comprender ni creer ${ }^{55}$.

Este detalle que, con frecuencia, pasa desapercibido, resultaba de crucial importancia, y Erasmo, además de ser certero en el mismo, coincide con la visión más propia de la nueva preocupación por la predicación. Aquella que tendrán también en Italia o en España. Una reforma de la Iǵlesia sostenida en los movimientos de observancia, pero que es también la misma que mueve a Lutero o a Melanchton. Para todos ellos había un elemento homilético central: el ejemplo del Maestro.

En la comprensión de los humanistas elocuencia y conocimiento eran dos realidades estrechamente vinculadas y, prácticamente, inseparables. Y el predicador debía ordenar sus ejemplos, esquemas y lugares comunes de tal suerte que cautivara al pueblo de lo que estaba proclamando, por lo que era preciso que esto fuera también acompasado por una coherencia de vida. En este sentido, los ejemplos tenían la finalidad de persuadir a su audiencia, orientándolos e inspirándolos a la virtud. No se trataba solo de contemplar la vida de Cristo, sino que esta fuera la inspiradora del hacer y sentir de las gentes. Se trataba no solo de comunicar la piedad, sino de vivir en ella, de usar la predicación como un medio de persuasión, no insistiendo tanto en la proclamación o enseñanza, pero haciendo que esta fuera efectiva.

La responsabilidad que se encomendaba al predicador era conducir a una vida virtuosa, que tenía como prototipo el Evangelio, que, además, tenía la función

\footnotetext{
53 Erasmus Roterodamus, «Apophtheǵmata», LB IV, cols. 478-479.

${ }^{54}$ O’Malley, 1983, p. 240.

${ }^{55} L B \mathrm{~V}$, col. 859.
} 
y necesidad de ser predicado. Esa vida virtuosa, por tanto, era una coherencia interna necesaria entre la propia vida del predicador y la permanente confrontación con la Escritura. El predicador debía ser un hombre 'amoldado' al Evangelio.

De esta manera se entiende que, en su comprensión, la Escritura ocupe un papel trascendental en la predicación. Por lo que son los mismos relatos los que han de determinar el orden en que se debía organizar el sermón, animando a los predicadores a que, en su preparación, siguiesen el propio movimiento que surǵía del texto o pasaje que estaban estudiando (col. 953). Este detalle aparece todavía más plausible al notar que Erasmo dedica una larǵa sección a la exégesis del texto que ha de ser comentado (cols. 1019-1067).

Por otra parte, los argumentos extraídos de la Escritura tenían un valor superior a aquellos que provenían de la razón humana. Son el camino más seguro para la Iǵlesia, que tiene un valor singular en el Nuevo Testamento, entendiendo el Evangelio y el mensaje cristiano como clave permanente de verificación. El predicador tenía que ser capaz de crear en su auditorio una capacidad de escucha, de interioridad, que luego llevara también a la acción. Y, en este sentido, el anuncio del mensaje de salvación tenía que ser parte de la misión que le correspondía al predicador: que el oyente descubriera el itinerario de fe hacia el que estaba llamado.

\section{San Juan de Ávila: una vida dedicada a la predicación}

Queremos ahora, en último lugar, acercarnos a una figura que fuera capaz de expresar no solo un proyecto teórico, como es el caso de Erasmo, sino que su vida estuviera surcada y guiada por esa causa: la predicación misionera. En el marco previo a Trento nos encontramos, en Castilla, con dos figuras que cumplen esas condiciones: Juan de Ávila y Tomás de Villanueva. Optamos por escoger al primero, pues es en esa condición de predicador como lo identifican sus primeros biógrafos ${ }^{56}$. García Villoslada lo define como «un predicador apostólico, un celoso reformador, un espiritual troquelado en san Pablo» ${ }^{57}$. Un intelectual que tiene la

${ }^{56}$ En esta misma línea, fray Luis de Granada en el prólogo de la vida del Maestro Ávila -sin perder de vista que se trata de un género hagiográfico- afirmará: «Que aproveche a los hermanos, y especialmente a los que están dedicados al oficio de la predicación: porque en este predicador evangélico verán claramente, como en un espejo limpio, las propiedades y condiciones del que este oficio ha de ejercitar».

${ }^{57}$ García Villoslada, 1970, p. 627. La idea aparece ya presente en su primer biógrafo, el licenciado Muñoz: «hizo particular estudio en las Epístolas de san Pablo; llegó a saberlas de memoria; fue su principal caudal. Cuando comenzó a predicar había en España muy moderadas letras, y muy poca inteligencia de las Epístolas del Apóstol, de las grandes profundidades y misterios que en 
singularidad de pasar todo por el tamiz de la experiencia de Dios y, desde ahí, llevarlo a la acción, fundamentalmente por medio de la predicación y el acompañamiento espiritual. Es un hombre obsesionado por transmitir el mensaje del Evangelio, lo que le lleva también a preocuparse por la educación y la catequesis, así como por múltiples iniciativas sociales. Quiere lograr una elevación de la educación reliǵiosa del pueblo y, a este fin, la predicación la entiende como uno de los instrumentos más eficaces.

No se puede perder de vista que el Maestro Ávila trabajará en un entorno particularmente complejo. Si como señalara el profesor Márquez Villanueva, en los reinos peninsulares la atención a la predicación «había sido de siempre deficitaria» ${ }^{58}$, lo era mucho más en Andalucía. El mundo rural había estado totalmente desasistido de una atención religiosa que acompasara la vida del pueblo. Y cuando este había tenido algún tipo de atención, había sido de corte ritualista y superficial. Este detalle preocupará a diversos autores de este momento, entre los que se cuenta también el Maestro Ávila. Los predicadores preferían actuar en las ciudades, huyendo así de una vida más dura y exiǵente ${ }^{59}$.

Consciente de esta situación, con el talante apostólico que le habían inculcado en la Universidad de Alcalá -entre otros Pedro Ciruelo ${ }^{60}-$, Ávila diseña un proyecto de formación integral del pueblo, que se va completando con la puesta en marcha de diversas obras, por una parte, pero también con una dedicación permanente a la predicación y a la relación humana directa. Como buen pedagogo, plantea un proyecto que permanezca en medio de la gente, evitando acciones puntuales o que mirasen a lo extraordinario. Su plan incide en una especie de proyecto permanente y, por lo mismo, también sistemático. Pero al asumir dicho plan debía hacer hincapié en las necesidades de los distintos grupos sociales, consciente de que las necesidades que requerían no eran las mismas. Esto suponía no hacer acepción de personas y estar abierto a todos, pero con la capacidad de dar a cada uno aquello que le era más necesario. En esto insiste el profesor Márquez Villanueva: «Sus páginas saben dar un tono medio, cuya claridad y ausencia de afectación le permite comunicar lo mismo con iǵnorantes que con sabios, sin asomo de renuncia al alto compromiso de su compleja y renovada teología del amor divino ${ }^{61}$. No se puede olvidar, en este sentido, que allí donde Lutero había puesto la fe, el santo Maestro pondrá el amor, algo tan

ellas están encerrados. Este gran padre trabajó mucho por penetrar estos secretos; comenzó a explicarlas, y citarlas en el púlpito con grande agudeza, y subtileza, diciendo cosas maravillosas». Muñoz, Vida, lib. I, cap. 7.

58 Márquez Villanueva, 2002, p. 91.

${ }^{59}$ Esta cuestión la aborda en la primera parte del Memorial I al Concilio de Trento (1551).

${ }^{60}$ Véase Pena González, 2013, pp. 378-391.

${ }^{61}$ Márquez Villanueva, 2002, p. 92. 
frecuente en los cristianos de ascendencia conversa. Y, precisamente, de esto se trataba, de vivir una experiencia amorosa, en la cual el encuentro entre Cristo y el cristiano era fundamental, lo cual se trasluce a lo largo de toda su obra. Así lo expresa él: "Pues quien dice que te conoce como te ha de conocer y no te ama, es mentiroso. Amémoste, pues, y conozcámoste por el conocimiento que de amarte resulta» ${ }^{62}$.

También Ávila plantea la reforma de la Iǵlesia, pero la entiende eminentemente en una clave interior. Así, mientras otros autores se preocupan por proponer una serie de obras a realizar y recorrer, él presenta un camino de implicación personal, al que se añadirán luego unas acciones concretas. Este camino tiene que ver con su propia experiencia, como consecuencia del recorrido vital que había hecho en las universidades de Salamanca y Alcalá ${ }^{63}$. Por lo mismo, el fin no ha de estar solo en el cumplimiento de unas normas, sino que habrá que buscar también la virtud. Y, en relación a los ministros ordenados, esto ha de ser realizado con sumo mimo y cuidado. Considera que a la Iglesia le compete una tarea fundamental e irrenunciable, que permite la vinculación personal y comunitaria: criar candidatos idóneos, con una buena selección y formación ${ }^{64}$. Él propondrá un recorrido de ocho años, para que fueran educados antes que ordenados.

Una vía fundamental estaba en la formación, en la cualificación de candidatos idóneos para dicho ministerio. Por lo mismo, delinea un perfil de cómo ha de ser su formación. Es interesante comprobar que él está considerando un itinerario formativo específico para aquellos que se han de dedicar a la predicación, entendiendo que no se trata solo de una formación de corte intelectual. Lo importante es

salir muy doctos lectores y predicadores, a los cuales se les puede encomendar sin miedo el tesoro y la alteza de la palabra de Dios... pues el oficio de predicar es de mayor peligro y pide mayor santidad; la cual faltando, tórnanse las más grandes letras en más grandes armas para todo mal ${ }^{65}$.

62 Ávila, Carta 64. A unos amigos suyos, vol. IV, p. 287.

${ }^{63}$ Piénsese, a este respecto, en algunas expresiones de difícil comprensión y explicación, como cuando se refiere a su etapa salmantina y habla de las «leyes neǵras». No deja de estar presente una comprensión, también muy vinculada con el mundo converso, que la opción no puede estar sustentada en el hacer cosas, sino que tiene que haber una profunda experiencia y vivencia interior; construir el hombre nuevo, desde lo que es.

${ }^{64}$ A este respecto, en las Advertencias necesarias para los reyes insistirá en que han de promover una selección cuidadosa de aquellos que quieran ser promovidos a una tarea ministerial, poniendo el acento en obispos, beneficiados, confesores y predicadores. Su comprensión entiende que han de ser espejos de un vivir evangélico. Ávila, Advertencias necesarias para los reyes [nn. 4, 22], vol. II, pp. 630, 639-640.

${ }_{65}$ Ávila, Memorial primero al Concilio de Trento (1551). Reformación del estado eclesiástico [n. 15], vol. II, p. 494. 
Los dedicados a la predicación debían formarse en positivo o estudios bíblicos, no en retórica ${ }^{66}$, pues parte del principio, casi común en todos aquellos que muestran especial atención a la predicación en este momento, de que «los escolásticos no son buenos para el púlpito ${ }^{67}$. Pero, en este sentido, es interesante constatar que la comprensión global que tiene del itinerario que ha de hacer el hombre le lleva a poner la fuerza no en los medios que ha de utilizar, sino mirando a lo esencial, los fines que persigue. No cabe duda de que se trata de una perspectiva interiorizante, interpretando y proponiendo el itinerario de vida cristiana como un camino que se ha de recorrer. En ese iter, junto con la fe, estaría el mismo ejemplo de Cristo y el amor, que se alimentarían por medio de la oración, el amor y el servicio. Sus palabras resultan elocuentes: «Para lo mucho y para lo poco nuestra confianza sea nuestro Señor, y la pobreza los medios ${ }^{68}$.

Considera que aquellos que se están preparando para la predicación, requieren un buen conocimiento de «la más alta y señora» de todas las disciplinas, que no es otra que la Saǵrada Escritura. En este sentido afirma:

los que toman oficio de predicar habiendo solamente oído teología escolástica, lo hacen muy desaprovechadamente, de lo cual está la razón manifiesta, pues la ciencia que hace llorar y purificar los afectos... en la Sagrada Escriptura... está; y, como de esto estén ayunos, no pueden dar provechoso pasto a las ovejas, antes algunas veces suelen contradecir a los que lo dan. Mándese que, antes que prediquen, hayan oído, después de la teología escolástica, tales y tales libros de la Escriptura divina y estudiándolos con diligencia, en lo cual sean examinados ${ }^{69}$.

Esto implicaba, como en el caso de Erasmo, poner la palabra de Dios en el centro, pero teniendo claro que había de ser estudiada, conocida y amada. Era tenerla como elemento fundamental de discernimiento, que se verifica particularmente a partir de Cristo. Así se lo había planteado ya a doña Sancha Corrillo, en aquella obra espiritual que será el Audi, filia, pero no cabe duda de que se convierte en un elemento fundamental del seguimiento, que los predicadores han de ser capaces de transmitir adecuadamente al pueblo, lo que entrañaba abrirse a la dialéctica que era la vida de Cristo: «Mirad, pues, a Cristo, porque os mire Cristo a $\operatorname{vos} »^{70}$. Aplicado a la predicación, Ávila prescinde abiertamente del sermón culto,

${ }^{66}$ La preocupación por la formación bíblica es un lugaar común. En su caso, iǵual que sucediera en Erasmo, se convierte casi en una obsesión. El sacerdote ha de predicar con un buen sustrato bíblico.

${ }^{67}$ Ávila, Memorial segundo al Concilio de Trento (1561). Causas y remedios de las herejías [n. 67], vol. II, p. 591.

${ }_{68}$ Ávila, Audi, filia [II], cap. 70, vol. I, p. 687.

${ }_{69}$ Ávila, Memorial II al Concilio de Trento, [n. 69], vol. II, p. 593.

${ }^{70}$ Ávila, Audi, filia [II], cap. 112, vol. I, p. 777. 
orientándose hacia uno pastoral, que podríamos denominar también ya como homilía, coincidiendo en esto con lo propuesto por figuras tan diversas como los humanistas Erasmo y Melanchton. Sí era frecuente, como hemos señalado, que el predicador siguiera luego con las confesiones o las consultas particulares, en el caso del Maestro Ávila esto se entendía también como una prolongación de ese ministerio singular, pues había loǵrado mover el corazón de las gentes.

Se intuye que la predicación debía sustentarse en el kerigma, olvidándose de otros adornos o retóricas, que desviaban la atención de lo fundamental. El predicador, por lo mismo, debía trasparentar la bondad, pues con ello ayudaría a que las letras resultasen más comprensibles, no solo por la coherencia de vida, sino también por el hecho de que el auditorio podía sentirse más atraído por un lenguaje elocuente ${ }^{71}$. De igual manera, la predicación debía, de una manera $u$ otra, poner a Cristo en el centro, teniendo presente que todo lo demás había de someterse a este principio: «Los que predican reformación de la Iǵlesia, por predicación e imitación de Cristo crucificado lo han de hacer y pretender» ${ }^{72}$.

Considerará la necesidad de que el predicador prepare adecuadamente aquello que ha de pronunciar $^{73}$, de tal suerte que sea capaz de conjugar ciencia, amor y elocuencia en un equilibrio adecuado que, por otra parte, no había de ser siempre el mismo. Esta última, tal y como veíamos ya en Melanchton, la entiende como una persuasión activa, que implica mover el deseo y la voluntad en el oyente. Por lo mismo, en la persona del predicador esto se convierte, a un mismo tiempo, en un don y una tarea, por la misma responsabilidad que implica dicho ministerio: «Gran diǵnidad es traer oficio en que se ejercitó el mismo Dios, ser vicario de tal Predicador, al cual es razón de imitar en la vida como en la palabra» ${ }^{74}$. En definitiva, entendía que el predicador tenía que ser consciente de ser una mediación, por lo que unas líneas más adelante sostendrá que no debía orientarse por su interés personal, mirando

a otra parte sino a la gloria de Dios, y ésta busquemos, y de ésta seamos pregoneros; que quien mira a la propria es semejante al que fuese a decir a una doncella que la quería por mujer el hijo del rey, si ella quería dar su consentimiento, y el tal mensajero granjease para sí la que había de ganar para el hijo del rey. (pp. 29-30)

71 «hábiles para ser abogados por el pueblo de Dios... y aprendan principalmente bondad, y después letras, para que puedan ser sin peliǵro maestros y edificadores de ánimas». Ávila, Memorial I al Concilio de Trento, [n. 12], vol. II, p. 492. Él mismo era un ejemplo de este proceder. Así lo afirma fray Luis de Granada, pues «no sabía si el padre Ávila ganó más almas para Dios con sus palabras o con su caridad». Granada, Vida..., cap. II.

72 Ávila, Plática 4. Recordar e imitar la passion de Jesucristo, vol. I, p. 827.

${ }^{73}$ «Que se estudie el sermón durante tres o cuatro días antes sin congoja, y el día antes del sermón ocuparlo en gustar lo que ha de decir, y no predicar sin estudio ni sin este día de recogimiento particular». Ávila, Carta 5. A un predicador, vol. IV, pp. 39-40.

${ }^{74}$ Ávila, Carta 4. A un predicador, vol. IV, p. 29. 
Volviendo sobre su proyecto y la vinculación estrecha que tiene con la predicación, no hay duda de que él propondrá algunas innovaciones que se concretarán en su ratio studiorum, donde incorpora el trabajo práctico en la asistencia espiritual del pueblo. No es cuestión aquí de detenernos en valorar cómo esto ha de ser interpretado, pero no cabe duda de que tiene una importancia significativa. Configura la formación universitaria con un talante y estilo diverso al clásico, que era promovido por una universitas que vivía de una tradición ya bastante agostada. Respondía a ese talante marcado por una predicación misionera; aquel que había acompañado su itinerario por Alcalá, pero que ahora estaba pasado por el crisol de la propia experiencia.

Así, de manera concreta, en 1545, funda en la Universidad de Baeza la primera cátedra de teología positiva en el mundo universitario ${ }^{75}$. Era una respuesta que tenía mucho que ver con su formación, pero que respondía también a un espíritu práctico, que no se conformará con lo que se ha hecho siempre, sino que intenta dar respuestas a cada necesidad. Y a este fin, no hay duda de que la teología positiva podía dotar a los bachilleres en teología de unas herramientas mucho más oportunas, tanto para su formación personal como para la proyección en el pueblo. Y, como ponía de relieve la profesora Rincón,

la preocupación sobre el tema de la predicación en Juan de Ávila respondía a su vocación catequética y pedagógica. De ahí que, en el contexto de Baeza, resulte imprescindible relacionar la didáctica de la oratoria y el sermón con el catecismo. Se concebía la formación del cristiano a través de la enseñanza de la doctrina a través del catecismo, o la explicación de las Escrituras por medio del sermón ${ }^{76}$.

En lo que se refiere a la organización de los estudios logrará un mayor aprovechamiento del año escolar facilitando incluso, tal y como se refleja en los primitivos Estatutos de Baeza, que los grados se pudieran obtener en menos tiempo ${ }^{77}$. Esos años de estudio eran completados, de manera obligatoria, con una experiencia pastoral antes de la obtención del grado académico.

No incorpora únicamente un proyecto teórico, al estilo de los que la Compañía de Jesús hará mediante su ratio studiorum, sino que vincula ya el trabajo práctico apostólico, concretado en la asistencia espiritual al pueblo, mediante la cura de almas y la predicación, suponiendo esta manera de hacer una verdadera novedad. Sería necesario, a este respecto, valorar qué concepto de Uni-

\footnotetext{
${ }^{75}$ Véase Andrés, 1976, p. 41.

${ }^{76}$ Rincón, 2006, p. 136.

${ }^{77}$ Ximénez Patón, Historia de la antigua y continuada nobleza..., p. 98.
} 
versidad o estudios superiores tiene el santo Maestro. El suyo es un proyecto integrador, en medio de las necesidades sociales y que vive el pueblo, por lo que el estudio no se entiende solo como una oportunidad para el propio individuo y su promoción, sino que se ha de proyectar hacia la sociedad como servicio y vocación. El ideal de clérigo que proyecta su comprensión acerca de qué es la Academia, por tanto, tiene una fuerte carga misionera, en la que consideraba necesaria una profunda claridad de ideas y una vida exigente. Entendía la misma como la última pieza de todo un sucesivo entramado educativo en el cual, la predicación, por una parte y, la doctrina cristiana, por la otra, seguían siendo dos elementos de singular importancia que, además, debían ser comprendidos en una doble dirección. Precisamente por ello insistirá en que también los docentes reciban y escuchen la doctrina cristiana. Sus palabras resultan un verdadero modelo de organización: «Téngase mucho cuidado de buscar maestros de buenas costumbres, [...] y procúrese alguna persona religiosa que haga pláticas a dichos maestros» ${ }^{78}$.

Sorprende el hecho de que no teorice sobre el predicador, sino que habla de la predicación. En este sentido, se refiere al predicador como aquel que ha de tener una vivencia propia del misterio de Dios y, al mismo tiempo, del ministro que ha de guiar a otros en ese camino. En relación a la necesidad de un contacto con Dios, cultivado por medio de la oración, el Maestro está teniendo presente también el De doctrina christiana de san Agustín, mostrando cómo no será algo que alcance el hombre por sus propios medios. Para ello, el predicador ha de recorrer un itinerario, que él irá describiendo de manera familiar en sus cartas, entendidas primero para un contexto concreto y particular, pero que ahora se convierten en un estilo de vida, aparejada por unas herramientas y prácticas que debían ser un itinerario.

y el estudio será comenzar a pasar el Nuevo Testamento, y si fuese posible, querría que lo tomase de coro. El estudio será, alzando el corazón al Señor, leer el texto sin otra ǵlosa, si no fuere cuando algo durare, que entonces puede mirar o a Crisóstomo, a Nicolao, o a Erasmo, o a otro que le parezea que declare la letra no más; y no se meta sino en saber el sentido propio que el Señor quiso allí entender ${ }^{79}$.

78 Ávila, Carta 11. A un señor de este reino, siendo asistente de Sevilla, vol. IV, p. 83.

79 Ávila, Carta 5. A un predicador, p. 36. En la misma línea, con algún elemento que completa y resulta particularmente sugerente: «Y llamo estudiarlo el mirar el sentido propio de él, el cual algunas veces está claro, y otras es menester mirar algún doctor. Y de éstos sean los principales Jerónimo y Crisóstomo; y también puede mirar la Paraphrasis de Erasmo, con condición que se lean en algunas partes con cautela...; y para el estudio del Nuevo Testamento aprovecha mucho un poco de grieǵo, por poco que fuese, y haya las Anotationes de Erasmo, que en gran manera le aprovecharán para esto». Ávila, Carta 225. A un discípulo, vol. IV, p. 724 


\section{Conclusiones}

Con todo esto, se constata cómo, en un momento de profunda decadencia en la vivencia cristiana, la predicación sagrada superó la aridez conceptual, de corte academicista de los escolásticos, permitiendo al pueblo un contacto vivo y auténtico con los misterios divinos. Esto, además, se hacía volviendo a las fuentes, principalmente a la Escritura y los Padres, además de la recuperación de las artes oratorias. Es cierto que, en razón de los diversos lugares, esto tendrá unos matices diferentes, pero siempre en la misma línea de principios.

Melquíades Andrés Martín afirmaba que el ideal de predicador evangélico de Erasmo y del Maestro Ávila son muy diversos ${ }^{80}$, pero, aun siendo esto verdad, hay que reconocer que no deja de sorprender la sintonía tan grande que tienen en múltiples cosas, máxime teniendo en cuenta que pertenecen a generaciones diversas e, incluso, a dos épocas bien diferentes, sin olvidar que su formación y recorrido vital son también diversos. Por otra parte, parece necesario dar la importancia que se merece al hecho de que la sintonía es en elementos esenciales de la vivencia cristiana del siǵlo XVI, la imagen de Cristo, el paulinismo, la reforma de la Iǵlesia... que se concretan luego en matices y formas particulares en cada uno. En este sentido es cierto que unos pondrán el acento más en los medios, y otros, directamente en los fines.

En relación al paulinismo, no cabe duda de que es un elemento que tiene una gran fuerza en la mayoría de los autores de la época. En este sentido no siempre es fácil delimitar cuáles son las influencias, pero es seguro que la Universidad de Alcalá es uno de los vehículos de transmisión, particularmente en el periodo histórico que nos ocupa ${ }^{81}$, y que estaba también en franca dependencia de lo que se venía haciendo en otros lugares y de lo que proponían otros autores, como será el caso del mismo Erasmo.

El tema de la predicación previa a Trento ha de ser estudiado y revisado en profundidad, pues al ponerse el acento en los ars praedicandi, como resultado de las reflexiones y decretos conciliares, se apagó esa chispa de innovaciones y de intuiciones personales, que surgen por todas partes. Y, en este orden de cosas, no cabe duda de que uno de los conceptos con los que se ha de poner en diálogo es el de reforma, que recorre gran parte de la historia religiosa europea.

\footnotetext{
${ }^{80}$ Véase Andrés Martín, 2002, p. 176.
}

81 Véase García Muñoz, 2014, p. 314. 


\section{Bibliografía}

Álvarez Turienzo, Saturnino, «Las universidades de Salamanca y Alcalá como formas rivales de educación», en Homenaje a Pedro Sáinz Rodríguez. III. Estudios históricos, Madrid, Fundación Universitaria Española, 1986, pp. 37-55.

Andrés Martín, Melquíades, La teología española, vol. I, Madrid, BAC, 1976.

Andrés Martín, Melquíades, «Erasmo (1466-1536) y Juan de Ávila (1500-1569): en torno a su humanismo y espiritualidad», en «El Maestro Ávila». Actas del Congreso Internacional, Madrid, CEE, 2002, pp. 171-194.

Asensio, Eugenio, El erasmismo y las corrientes espirituales afines. Conversos, franciscanos, italianizantes con algunas adiciones y notas del autor, $2^{\mathrm{a}}$ ed., Salamanca, Semyr, 2000.

Ávila, Juan de (santo), Obras Completas. I. Audi, filia - Pláticas - Tratados, Luis Sala Balust y Francisco Martín Hernández (eds.), Madrid, BAC, 2000.

Ávila, Juan de (santo), Obras Completas. III. Sermones, Luis Sala Balust y Francisco Martín Hernández (eds.), Madrid, BAC, 2002.

Ávila, Juan de (santo), Obras Completas. IV. Epistolario, Luis Sala Balust y Francisco Martín Hernández (eds.), Madrid, BAC, 2003.

Ávila, Juan de (santo), Obras Completas. II. Comentarios bíblicos - Tratados de reforma - Tratados y escritos menores, Luis Sala Balust y Francisco Martín Hernández (eds.), Madrid, BAC, 2013.

Bataillon, Marcel, «Hacia una definición del eramismo», en Marcel Bataillon, Erasmo y el erasmismo, Barcelona, Crítica, 2000, pp. 141-161.

Bédouelle, Guy, La Réforme du catholicisme (1480-1620), París, Cerf, 2002.

Campagnola, Stanislao da, Oratoria sacra. Teologie, ideologie, biblioteche nell'Italia dei secoli XVI-XIX, Roma, Istituto Storico dei Cappuccini, 2003.

Campos Vargas, Henry, «La(s) retórica(s) en el Renacimiento», Revista de Lenguas Modernas, 10, 2009, pp. 215-223.

Cátedra, Pedro M., «Nebrija y la predicación», en Carmen Codoñer y Juan Antonio González Iglesias (eds.), Antonio de Nebrija: Edad Media y Renacimiento, Salamanca, Universidad de Salamanca, 1994, pp. 129-150.

Ciruelo, Pedro, Expositio libri missalis peregregia. Addita sunt [et] tria eiusdem autoris opuscula. De arte predicandi, De arte memorandi et De correctione kalendarij, in praeclara universitate Complutensis, in aedibus Michaelis de Eguía, 1528.

Ciruelo, Pedro, Reprobación de las supersticiones y hechizerías, libro muy útil, y necessario a todos los buenos christianos, Alcalá, Pedro de Castro, 1530.

Ciruelo, Pedro, Confessionario. Es arte de bien confessar, muy provechosa al confessor y al penitente; en el qual están agora nuevamente añadidos muchos apuntamientos en muchos lugares..., Medina, Pedro de Castro, 1544.

Ciruelo, Pedro, Contenplaciones muy devotas sobre los misterios sacratíssimos de la pasión de Nuestro redemptor Iesu Christo. Juntamente con un tratado de la mystica teología para los devotos que se han retraído a la vida solitaria contemplativa, Alcalá de Henares, en casa de Juan de Brocar, 1547. 
Ciruelo, Pedro, Cuádruple versión del Génesis, M. Pérez y Rodríguez (ed.), t. I, Madrid, Impr. Asilo de huérfanos, 1914.

Concilium Lateranense V, en Conciliorum Oecumenicorum Decreta, Giuseppe Alberigo et al. (ed.), Bologna, EDB, 1991, pp. 593-655.

Deza, Diego de, In defensione sancti Thomae ab impugnationibus magistri Nicholai magistrique Mathiae propugnatoris sui, Hispalis, 1491.

Dyck, Joachim, «El primer tratado alemán sobre el arte de la oratoria sagrada. El Pastorales de Erasmus Sarcer y la retórica clásica», en James J. Murphy (ed.), La elocuencia en el Renacimiento. Estudios sobre la teoría y la práctica de la retórica renacentista, Madrid, Visor, 1999, pp. 263-282.

Erasmus Roterodamus, Desiderius, «Apophthegmata», en Desiderii Erasmi Roterodami Opera Omnia, Johannes Clericus (ed.), vol. IV, Hildesheim, 1962.

Erasmus Roterodamus, Desiderius, «Ecelesiastes sive de Ratione Concionando Libri Quatuor (1535)», en Desiderii Erasmi Roterodami Opera Omnia, Johannes Clericus (ed.), 1962, vol. V, Hildesheim, cols. 796-1100.

García Hernán, Enrique, Ignacio de Loyola, Madrid, Taurus, 2013.

García Muñoz, Manuel, «El biblista san Juan de Ávila», en María Dolores Rincón y Raúl Manchón (eds.), El Maestro Juan de Ávila (1500?-1569). Un exponente del humanismo reformista, Madrid, FUE, 2014, pp. 299-319.

García Villoslada, Ricardo, «El paulinismo de san Juan de Ávila», Gregorianum, 51, 1970, pp. 615-647.

Giustiniani, B. Pauli, y Petri Quirini, Libellus Addressed to Leo X, Supreme Pontiff, Ian Christopher Levy, Stephen M. Beall y John J. Schmitt, Marquette (eds.), University Press, 2016.

González Novalín, José Luis, «Religiosidad y reforma del pueblo cristiano», en José Luis González Novalín (dir.), Historia de la Iǵlesia en España. III-1. La Iglesia en la España de los siglos XV y XVI, Madrid, BAC, 1980, pp. 351-384.

Grace, Carmen H., «Sobre la predicación culta en el Siǵlo de Oro: polémicas y retóricas cristianas», The Bulletin of Hispanic Studies, 93.9, 2016, pp. 963-980.

Kleinhaus, Robert G., «Eramus' Doctrine of Preaching. A Study of Ecclesiastes, sive de ratione concionandi», tesis doctoral, Princeton, Theological Seminary, 1968.

López Muñoz, Manuel, "Nos ex Rhetorica quaedam concionum genera mutuatos esse”. Genera causarum y concionandi genera en el XVI español», Latomus, 59.1, 2000, pp. 129-146.

Márquez Villanueva, Francisco, «Vida y escritos de san Juan de Ávila a la luz de sus tiempos», en El Maestro Ávila. Actas del Congreso Internacinal, Madrid, GEE, 2002, pp. 77-98.

Melanchton, Philipp, «De officiis concionatoris», en Supplementa Melanchtoniana. II. Homiletische Schriften, Paul Drews y Ferdinand Cohrs (eds.), Leipzig, 1929, pp. 135-146.

Metz, Detlef, Gabriel Biel und die Mystik, Stuttgart, Franz Steiner, 2001.

Mezzadri, Luigi, Storia della Chiesa. Tra Medioevo ed epoca Moderna. 2. Rinnovamenti, separazioni, missioni. Il Concilio de Trento (1492-1563), Roma, CLV Edizioni, 2001. 
Minnich, Nelson H., «Concepts of Reform Proposed at the Fifth Lateran Council», Archivum Historiae Pontificiae, 7, 1969, pp. 163-251.

Muñoz, Luis, Vida y virtudes del venerable varón el P. Maestro Juan de Ávila, predicador apostólico, Barcelona, Juan Flors, 1964.

Nebrija, Antonio de, Hymnorum recognitio, Garnatam [sic], Sancho de Nebrija, 1541.

O'Malley, John W., «Erasmus and the History of Sacred Rhetoric: The Ecclesiastes of 1535», Erasmus of Rotterdam Society Yearbook, 5, 1985, pp. 1-29.

O'Malley, John W., «Content and Rhetorical Forms in Sixteenth-Century Treatises on Preaching», en J. J. Murphy (ed.), Renaissance Eloquence: Studies in the Theory and Practice of Renaissance Eloquence, Berkeley-Los Angeles-London, University of California Press, 1983, pp. 238-252. (Trad. al español, James J. Murphy (ed.), La elocuencia en el Renacimiento. Estudios sobre la teoría y la práctica de la retórica renacentista, Madrid, Visor, 1999, pp. 283-300).

Oberman, Heiko, The Harvest of Medieval Theology: Gabriel Biel and Late Medieval Nominalism, $2^{\mathrm{a}}$ ed., Cambridge, Harvard University Press, 2001.

Olmedo, Félix G., Nebrija (1441-1522). Debelador de la barbarie. Comentador eclesiástico. Pedagogo-poeta, Madrid, Editora Nacional, 1942.

Opus epistolarum Desiderii Erasmi Roterodami. IV. 1522-1524, Percy S. Allen y Helen M. Allen (eds.), Oxford, Clarendon Press, 1922.

Pastor, Víctor, «La filología bíblica de Antonio de Nebrija. De Valla a Erasmo», en Miguel Anxo Pena González e Inmaculada Delgado Jara (coords.), A quinientos años de la Políglota de Cisneros. Fuentes documentales y líneas de investigación, Salamanca, Universidad Pontificia de Salamanca, 2015, pp. 81-98.

Pena González, Miguel Anxo, «Tiempos y vivencias de san Juan de Ávila. Salamanca, Alcalá y Sevilla», en Juan Aranda Doncel y Antonio Llamas Vela (eds.), San Juan de Ávila, doctor de la Iglesia. Actas del Congreso Internacional, Córdoba, Diputación de Córdoba, 2013, pp. 371-398.

Rincón, María Dolores, «Criterios de selección en la Universidad de Baeza. Huarte de San Juan y los planteamientos avilistas», Elucidiario, 1, 2006, pp. 135-146.

Savonarola, Girolamo, «Compendio di riverlazioni» e «Dialogus de veritate prophetica», Roma, Angelo Belardetti Editore, 1974.

Schmitt, Charles B., "Gianfrancesco Pico della Mirandola and the Fifth Lateran Council», Archiv für Reformationsgeschichte/Archive for Reformation History, 61, 1970, pp. 161-178.

Tubau, Xavier, «El De doctrina christiana de san Agustín y las retóricas sagradas españolas del siǵlo XVI», Criticón, 107, 2009, pp. 29-55.

Vitrier, Jean, Spiritualité franciscaine en Flandre au XVI ${ }^{e}$ siècle. L'homéliaire de Jean Vitrier: texte, étude thématique et sémantique, André Godin (ed.), Genève, Librairie Droz, 1971.

Weiss, James M., «Ecclesiastes and Erasmus. The Mirror and the Image», Archiv für Reformationsgeschichte - Archive for Reformation History, 65, 1974, pp. 83-108.

Ximénez Patón, Bartolomé, Historia de la antigua y continuada nobleza de la ciudad de Jaén muy famosa, muy noble y muy leal guarda y defendimiento de los Reynos de España y de algunos varones famosos, hijos della, Jaén, 1628. 
